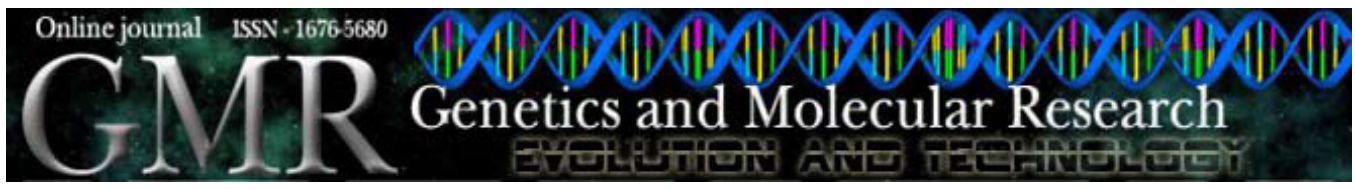

\title{
Genetic differences between strains of Biomphalaria glabrata (Planorbidae) that are susceptible and unsusceptible to schistosomiasis
}

\author{
A.L.D. Oliveira ${ }^{1,4,5}$, D. Da Silva ${ }^{2}$, B.C. Manzano ${ }^{2}$, A.Z. Abdel-Hamid ${ }^{6}$, \\ M.Y. Marcelino ${ }^{4}$, E.M. Zanotti-Magalhães ${ }^{3}$, L.A. Magalhães ${ }^{3}$ and \\ J.T. Ribeiro-Paes ${ }^{2}$ \\ ${ }^{1}$ Interunidades em Biotecnologia, \\ Universidade de São Paulo, São Paulo, SP, Brasil \\ ${ }^{2}$ Departamento de Ciências Biológicas, \\ Universidade Estadual Paulista, Assis, SP, Brasil \\ ${ }^{3}$ Departamento de Parasitologia, Instituto de Biologia, \\ Universidade Estadual de Campinas, Campinas, SP, Brasil \\ ${ }^{4}$ Departamento de Saúde, ADR-Biomavale, Assis, SP, Brasil \\ ${ }^{5}$ Departamento de Ciências da Saúde, \\ Universidade Paulista, Assis, SP, Brasil \\ ${ }^{6}$ Medicinal Chemistry Department, National Research Centre, \\ Dokki, Cairo, Egypt \\ Corresponding author: J.T. Ribeiro-Paes \\ E-mail: jtrpaes@yahoo.com.br / olivaldo3@yahoo.com.br
}

Genet. Mol. Res. 9 (3): 1450-1459 (2010)

Received April 12, 2010

Accepted May 19, 2010

Published July 27, 2010

DOI 10.4238/vol9-3gmr821

\begin{abstract}
Despite the implementation control programs, schistosomiasis continues to spread throughout the world. Among modern control strategies, vector control is currently being emphasized. Within this context, analysis of the genetic variability of intermediate host snails (Biomphalaria spp) is important because it allows identification of specific sequences of the genome of this mollusk related to suscep-
\end{abstract}


tibility/resistance to Schistosoma mansoni infection. We investigated Brazilian albino (non-pigmented) and pigmented (wild type) strains of Biomphalaria glabrata; these strains differ in their susceptibility to S. mansoni infection. Genetic variability was studied by RAPD-PCR using different random primers. The electrophoretic patterns resulting from amplification showed specific polymorphic markers for the albino and pigmented strains of B. glabrata. This information will help in the identification and isolation of genes specifically related to susceptibility, demonstrating that RAPD-PCR is an appropriate and efficient methodological approach for analysis of the genetic variability of schistosomiasis vectors.

Key words: Schistosoma mansoni; Biomphalaria; Polymorphism; Genetic variability; RAPD-PCR

\section{INTRODUCTION}

Despite the implementation of various institutional programs of global or regional coverage for the control of schistosomiasis and the relative success of some of them, especially the control obtained in Japan (Barbosa, 1995), schistosomiasis continues to spread all over the world. Today, it is one of the most serious public health problems, especially in third world countries (Mott, 1989), where it is closely associated with irrigation projects and with migratory movements (Dias et al., 1988; World Health Organization, 1993).

A considerable variety of strategies for vector control have been proposed within the general context of measures for reduction of schistosomiasis. Particularly important among them are the use of synthetic molluscicides such as niclosamide (Barbosa, 1995), molluscicides of plant origin (Jurberg, 1989; Schall et al., 1998), and also biological control using competitors and parasites of the mollusks (Paraense, 1987; Capron, 1993; Lardans and Dissous, 1998).

Biomphalaria glabrata (Say, 1818) has a wide geographic distribution and high susceptibility to Schistosoma mansoni (Sambon, 1907), thus representing the most important vector of schistosomiasis (Paraense et al., 1983; Teles and Vaz, 1987). This species also has a considerable degree of intraspecific polymorphism (Vidigal et al., 2000). Therefore, it is important to investigate the genetic variability related to the susceptibility to $S$. mansoni infection of mollusks, which are vectors of the genus Biomphalaria, both for a better understanding of the epidemiology of schistosomiasis (Paraense an Correa, 1978) and for the understanding of the parasite pathogenesis to its vertebrate host (Dias et al., 1988; ZanottiMagalhães et al., 1991, 1993, 1997).

Richards and Merritt Jr. (1972) used classical methods of genetic analysis, on the basis of which they proposed that the susceptibility of B. glabrata to $S$. mansoni infection may be regulated by at least four genes or, as defined by Larson et al. (1996), may be a polygenic trait. Richards et al. (1992) using classical genetic techniques, proposed that the susceptibility to the infection of B. glabrata by $S$. mansoni would show distinctive patterns related to the age of the mollusk. Thus, the resulting phenotype would be determined by several genes 
in the young mollusk and by only one gene in the adult. According to Mascara et al. (1999), the resistant phenotype would be the outcome of a great number of alleles present in a small number of loci or the outcome of few alleles in multiple loci in "linkage". The resisting phenotype would be the result of an "alteration" (change) in any of these different loci related to the susceptibility phenotype.

A series of molecular biology techniques have been used to study genetic variability in schistosomiasis vectors (Miller et al., 1996; Schall et al., 1998; Spatz et al., 1999; Caldeira et al., 2000; Janotti-Passos and de Souza, 2000; Knight et al., 2000; Vidigal et al., 2000; Raghavan et al., 2003; Da Silva et al., 2004).

In this study, we analyzed by random amplified polymorphic DNA-polymerase chain reaction (RAPD-PCR) the genetic variability between two strains (albino and pigmented) of $B$. glabrata with different degrees of susceptibility to $S$. mansoni infection.

\section{MATERIAL AND METHODS}

\section{Snail strains}

Adult B. glabrata snails (albino and pigmented strains) were originally from Belo Horizonte (MG, Brazil). They were maintained in our laboratory under suitable environmental conditions, in glass aquaria containing snail-conditioned water, and they were fed lettuce leaves and calcium carbonate.

\section{DNA extraction}

DNA was extracted from the tip of the head foot region of individual snails (albino and pigmented strains), using lysis buffer containing 2\% CTAB (Winnepenninckx et al., 1993; Abdel-Hamid et al., 1999) and incubated with proteinase $\mathrm{K}(2 \mu \mathrm{g} / \mathrm{mL})$ for $2 \mathrm{~h}$, followed by extraction with phenol, phenol:chloroform $(1: 1)$, chloroform:isoamyl alcohol (24:1) and incubation with ribonuclease A (350 $\mu \mathrm{g} / \mathrm{mL})$ (Spada et al., 2002, Oliveira et al., 2008). DNA was precipitated by adding isopropanol $(2: 3, \mathrm{v} / \mathrm{v})$ and leaving overnight at room temperature. After centrifugation, DNA was washed in $75 \%$ ethanol and $10 \mathrm{mM}$ ammonium acetate for $30 \mathrm{~min}$ and recovered by centrifugation $(7700 \mathrm{~g})$ for 10 min at $4{ }^{\circ} \mathrm{C}$. The pellet was resuspended in TE (10 mM Tris-HCl, $1 \mathrm{mM}$ EDTA, $\mathrm{pH}$ 8.0) and the DNA concentration and purity were determined spectrophotometrically (Spectrophotometer Ultrospec III - Pharmacia, UK) at 260 and $280 \mathrm{~nm}$, and by $2.0 \%$ agarose gel electrophoresis using the gel photodocumentation system (EDAS) DC 120 Zoom Digital Camera (Eastman Kodak, NY, USA).

\section{DNA amplification by RAPD-PCR}

The RAPD-PCR protocol used here was that described by Spada et al. (2002), with some modifications. Each individual sample and a pool of 3 individual samples of genomic DNA from snails of both strains of B. glabrata, at a concentration of $2 \mathrm{ng}$, were amplified in a reaction mixture $(10 \mu \mathrm{L})$ containing $1 \mathrm{U}$ Taq DNA polymerase (GIBCOBRL, MD, USA), 1X PCR buffer, 7 pmol of each random primer (10 bases), and $0.2 \mathrm{mM}$ 
of each dNTP. After DNA denaturation for 5 min at $95^{\circ} \mathrm{C}$, amplification consisted of 2 initial cycles of $30 \mathrm{~s}$ each at $95^{\circ} \mathrm{C}$ for denaturation, 2 min at $30^{\circ} \mathrm{C}$ for primer annealing, and $1 \mathrm{~min}$ at $72^{\circ} \mathrm{C}$ for extension. Thirty-two cycles were then performed with the annealing temperature being increased to $40^{\circ} \mathrm{C}$, and the extension period at $72^{\circ} \mathrm{C}$ was maintained for $5 \mathrm{~min}$ in the final cycle. The samples obtained were stored at $-20^{\circ} \mathrm{C}$.

Among the 10 primers used in this study (Table 1), the following primers (GIBCOBRL) 2 (5'-CTGATGCTAC-3'), 4 (5'-AGTGCTACGT-3'), 6 (5'-CAGGCCCTTC-3'), and 7 (5'-GGTCCCTGAC-3') were selected since they detected different markers between the two snail strains.

Table 1. Dice's similarity coefficient (*) between albino and pigmented strains of Biomphalaria glabrata snails.

\begin{tabular}{lccccc}
\hline Primers & P2 & P4 & P9 & P10 & P15 \\
\hline $\begin{array}{l}\text { Number of bands shared between } \\
\text { albino and melanic strains (a) }\end{array}$ & 36 & 24 & 46 & 22 & 29 \\
$\begin{array}{c}\text { Number of bands in albino } \\
\text { but not in melanic strains (b) }\end{array}$ & 0 & 2 & 0 & 1 & 0 \\
$\begin{array}{c}\text { Number of bands in melanic } \\
\text { but not in albino strains (c) }\end{array}$ & 1 & 1 & 1 & 0 & 0 \\
Similarity coefficient (S) & 0.98 & 0.94 & 0.98 & 0.97 & 1.00 \\
\hline
\end{tabular}

(*) $\mathrm{S}=2 \mathrm{a} / 2 \mathrm{a}+\mathrm{b}+\mathrm{c}$.

\section{Polyacrylamide gel electrophoresis and silver staining}

Electrophoresis was performed using an $8 \%$ polyacrylamide gel (29/1 acrylamide-bisacrylamide) in TBE buffer (90 mM Tris-borate, $2 \mathrm{mM}$ EDTA, $\mathrm{pH}$ 8), and applying a constant current of $60 \mathrm{~V}$. The gels were fixed in a mixture of $10 \%$ ethanol and $0.5 \%$ acetic acid $(\mathrm{v} / \mathrm{v})$ for 15 min and stained with silver nitrate (Santos et al., 1993).

\section{Analysis of polymorphisms on polyacrylamide gels}

The genetic variability of the strains was determined by analysis of the electrophoretic profiles of the bands visualized on the gels, and the similarity coefficient was calculated as described by Dice (1945).

\section{RESULTS}

The amplification experiments using RAPD-PCR with primer 2 (5'-CTGATGCTAC-3'), showed a 5000-bp band in the individual samples and in the pool of samples of the pigmented strain, as shown in Figure 1.

Figure 2 illustrates the results corresponding to the DNA amplification of the albino and pigmented strains of $B$. glabrata with primer 4 . Three polymorphic markers were obtained, where an 8300-bp band was present only in pigmented individuals and two bands of 8100 and $6900 \mathrm{bp}$ were detected only in albino individuals.

Amplification with primer 6 yielded a polymorphic marker, corresponding to a 3700bp band present only in the melanic strain, as indicated by arrow in Figure 3.

As shown in Figure 4, the amplification of genomic DNA of either the albino or pigmented strain with primer 7, revealed a 3800-bp band only detected in the amplified bands of the albino strain. 


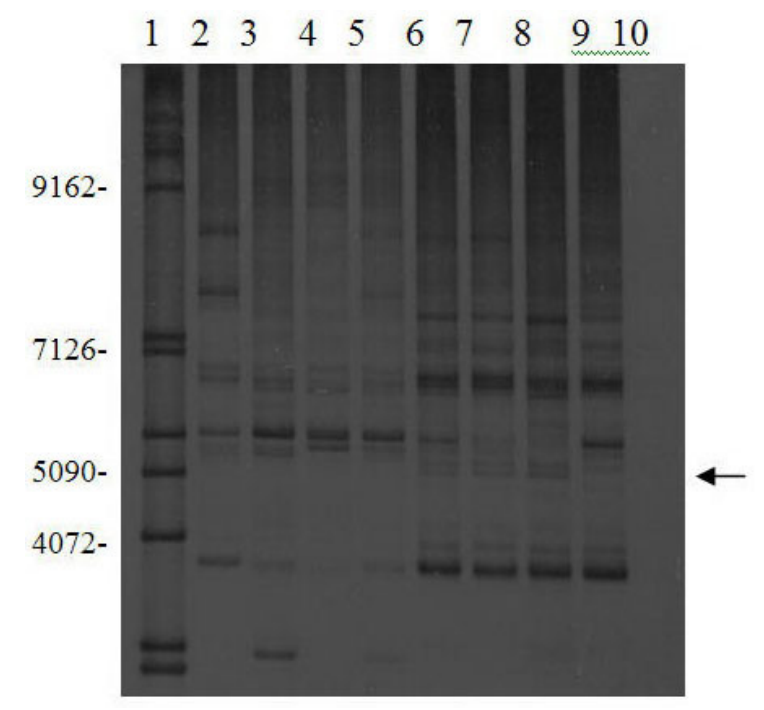

Figure 1. RAPD-PCR of genomic DNA of Biomphalaria glabrata albino and pigmented strains using arbitrary primer 2. Lane 1 = 1-kb DNA ladder; lane $2=\mathrm{A} 1$ (albino); lane $3=\mathrm{A} 2$ (albino); lane $4=\mathrm{A} 3$ (albino); lane $5=$ Pool A (A1, A2 and A3); lane 6= Pool M (M1, M2 and M3); lane $7=\mathrm{M} 1$ (pigmented); lane $8=\mathrm{M} 2$ (pigmented); lane $9=$ M3 (pigmented); lane $10=$ negative control (amplification without DNA). Samples were analyzed by $8 \%$ polyacrylamide gel electrophoresis with silver staining. Polymorphic bands are indicated by arrow.

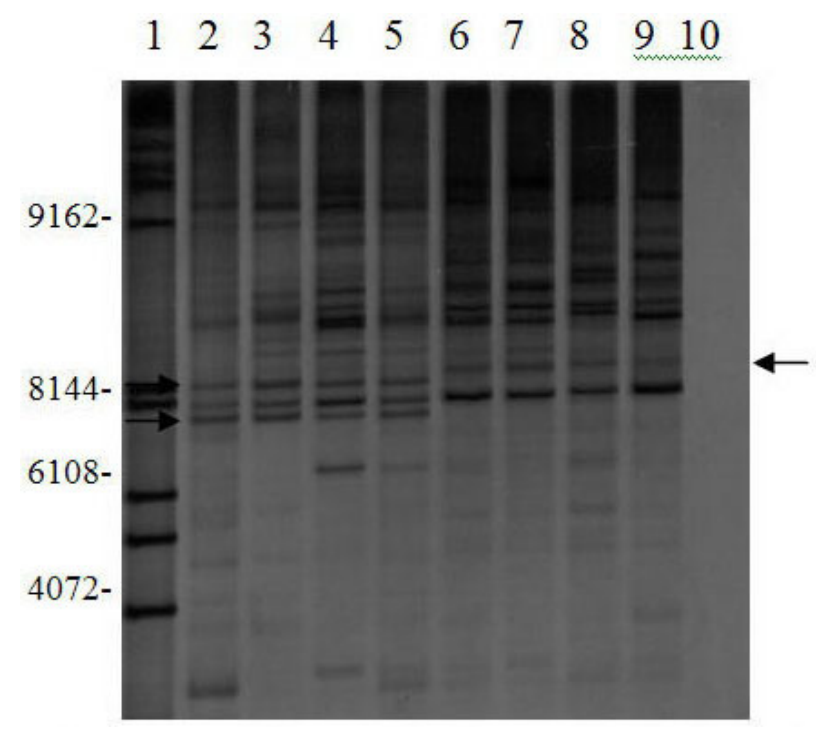

Figure 2. RAPD-PCR of genomic DNA of Biomphalaria glabrata albino and pigmented strains using arbitrary primer 4. Lane 1=1-kb DNA ladder; lane $2=\mathrm{A} 1$ (albino); lane $3=\mathrm{A} 2$ (albino); lane $4=\mathrm{A} 3$ (albino); lane $5=$ Pool A (A1, A2 and A3); lane $6=$ Pool M (M1, M2 and M3); lane $7=\mathrm{M} 1$ (pigmented); lane $8=\mathrm{M} 2$ (pigmented); lane $9=\mathrm{M} 3$ (pigmented); lane $10=$ negative control (amplification without DNA). Samples were analyzed by $8 \%$ polyacrylamide gel electrophoresis with silver staining. Polymorphic bands are indicated by arrows. 


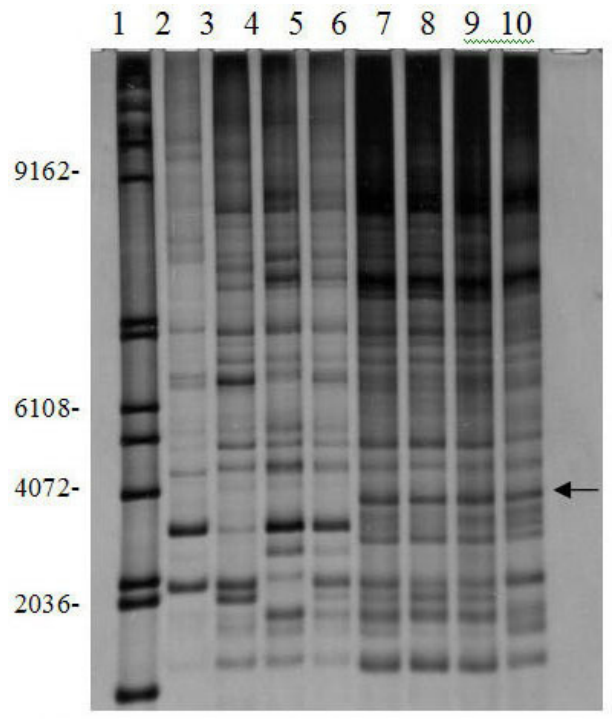

Figure 3. RAPD-PCR of genomic DNA of Biomphalaria glabrata albino and pigmented strains using arbitrary primer 6. Lane $1=1-\mathrm{kb}$ DNA ladder; lane $2=\mathrm{A} 1$ (albino); lane $3=\mathrm{A} 2$ (albino); lane $4=\mathrm{A} 3$ (albino); lane $5=$ Pool A (A1, A2 and A3); lane $6=$ Pool M (M1, M2 and M3); lane $7=\mathrm{M} 1$ (pigmented); lane $8=\mathrm{M} 2$ (pigmented); lane $9=\mathrm{M} 3$ (pigmented); lane $10=$ negative control (amplification without DNA). Samples were analyzed by $8 \%$ polyacrylamide gel electrophoresis with silver staining. Polymorphic bands are indicated by arrow.

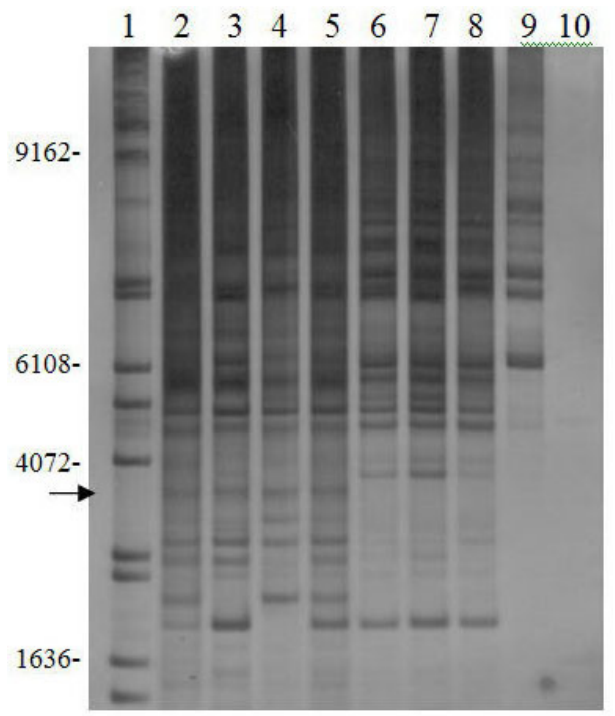

Figure 4. RAPD-PCR of genomic DNA of Biomphalaria glabrata albino and pigmented strains using arbitrary primer 7. Lane $1=1-\mathrm{kb}$ DNA ladder; lane $2=\mathrm{A} 1$ (albino); lane $3=\mathrm{A} 2$ (albino); lane $4=\mathrm{A} 3$ (albino); lane $5=$ Pool A (A1, A2 and A3); lane 6= Pool M (M1, M2 and M3); lane $7=\mathrm{M} 1$ (pigmented); lane $8=\mathrm{M} 2$ (pigmented); lane $9=\mathrm{M} 3$ (pigmented); lane 10= negative control (amplification without DNA). Samples were analyzed by $8 \%$ polyacrylamide gel electrophoresis with silver staining. Polymorphic bands are indicated by arrows. 
With the other primers, no band was obtained that could unequivocally characterize a polymorphic marker between the albino and pigmented strains.

\section{DISCUSSION}

As pointed out by Allegretti (1991), the pigmented strain is more susceptible to $S$. mansoni infection than the albino one. The results obtained by this author showed that about $72 \%$ of the pigmented strain examined were susceptible, in contrast to the albino strain of which $44.4 \%$ showed susceptibility. The author proposed that this phenomenon is under immunological regulation, since the infected pigmented strain shed more cercariae and noticed a high number of hemocytes in the infected albino strain.

Our results are of trials that formed part of screening procedures aimed to identify primers capable of distinguishing susceptibility of albino and melanic strains within B. glabrata species. The previous results obtained by different research groups (Larson et al., 1996; Abdel-Hamid et al., 1999; Spada et al., 2002; Da Silva et al., 2004) indicated that RAPD-PCR was an adequate technique and a good initial approach for distinguishing between closely related individuals in Biomphalaria snails. This methodology emphasizes our interest to determine genetic markers associated with two strains of $B$. glabrata using different primers.

The 10 primers tested in this study were adopted for having been used in prior studies in which specific polymorphic bands were detected in the snail vector (Biomphalaria) and/or in the parasite, as previously cited (Table 1). The results indicate that four of the 10 primers tested, 2, 4, 6, and 7, identified polymorphic markers as shown in Figures 1-4.

A 3700-bp polymorphic marker, which corresponds to the OPA-01 primer used by Larson et al. (1996), was obtained with primer 6. This band was detected only in the pigmented strain. Larson et al. (1996) obtained a 400-bp band characteristic of the susceptible strain (M-line) using the OPA-01 primer. This strain, obtained by Newton in 1955, combines the albino phenotype with a high susceptibility to infection with the Porto Rico strain of $S$. mansoni. The different origins of the M-line strain and of the melanic and albino strains used in the present study may explain the distinct polymorphic bands obtained by amplification with a primer with the same nucleotide sequence.

With primer 7, we obtained a polymorphic band of approximately $3800 \mathrm{bp}$, which was present only in the albino strain. This primer has the same sequence as the OPA-06 primer used by Larson et al. (1996), which led to the detection of a 1100-bp band for the susceptible M-line strain. A band of the same molecular weight was obtained with primer 10 for one of the susceptible B. glabrata strains (strain BH) maintained in our laboratory (Spada et al., 2002). This prompts us to question whether this marker is related to susceptibility in B. glabrata, and whether the 3800-bp band detected in the albino strain is related to resistance, considering that this strain has a low susceptibility to $S$. mansoni infection. These aspects are currently being studied in our laboratory using crosses and genetic analysis of the descendants resulting from the albino and pigmented strains and from crosses of strains resistant and susceptible to $S$. mansoni infection.

With the other primers, no specific or distinct polymorphic marker was detected between the two strains under study. It should be pointed out that similar results were obtained by Abdel-Hamid et al. (1999) with the same primer in Biomphalaria tenagophila.

A series of restrictions have been associated with RAPD-PCR procedures, mainly in 
reference to the generation of artifacts and the excess bands demonstrated in electrophoretic profiles (Riedy et al., 1992; Ellsworth et al., 1993; Matioli and de Brito, 1995). Matioli and Passos-Bueno (2001) also point out that a limitation of the RAPD technique is the lack of reproducibility in the results, between different laboratories. Nevertheless, the use of RAPDPCR techniques has been suggested for phylogenetic studies of individuals with narrow taxonomic relation (Rollinson et al., 1998). The errors of homology due to the use of RAPD may be reduced by an increase in the agarose concentration or by the use of a polyacrylamide gel electrophoresis system.

Although some studies have been carried out to define specific markers for susceptibility in B. glabrata by means of isoenzymes and analysis of pigmentation (Mulvey and Vrijenhoek, 1982; Mulvey and Woodruff, 1985), no marker is available to date that might safely be associated with susceptibility and/or resistance. However, Knight et al. (1999) analyzed F1 and F2 generations and the F1 versus parental backcross progeny through RAPD-PCR. This approach led to the identification of two markers, a 1200-bp band with the OPM-04 primer and a 1100-bp band with the OPZ-11 primer. These markers were found only in non-susceptible strains. This finding gives some support to the hypothesis that markers of segregation may be found in B. glabrata resistant to $S$. mansoni infection.

Although the studies of genetic variability of $B$. glabrata strains with different degrees of susceptibility to $S$. mansoni infection will lead to the development of new strategies for the control of schistosomiasis, as first proposed by Hubendick (1958) and later by others (Rollinson et al., 1998), they are still a matter of discussion. A series of technical difficulties must be overcome; nevertheless, these studies, as pointed out by Knight et al. (2000), should contribute to a better understanding of the correlations between vectors, parasites and transmission of the disease.

\section{ACKNOWLEDGMENTS}

Research supported by Fundação de Amparo à Pesquisa do Estado de São Paulo (FAPESP). The authors are grateful to Dr. Eliana M. Zanotti-Magalhães, Dr. Luiz A. Magalhães (Instituto de Biologia, UNICAMP) for helpful discussions and suggestions and to Ivo Gonçalves Pereira and João Batista Oliveira (Instituto de Biologia, UNICAMP) for technical support.

\section{REFERENCES}

Abdel-Hamid AZ, Molfetta JB, Fernandez V and Rodrigues V (1999). Genetic variation between susceptible and nonsusceptible snails to Schistosoma infection using random amplified polymorphic DNA analysis (RAPDs). Rev. Inst. Med. Trop. São Paulo 41: 291-295.

Allegretti SM (1991). Comportamento de Biomphalaria glabrata Variantes Albina e Melânica Frente a Infecção por Schistosoma mansoni. Universidade de Campinas, Campinas.

Barbosa FS (1995). Determination and control of schistosomiasis. Mem. Inst. Oswaldo Cruz 90: 155-159.

Caldeira RL, Vidigal TH, Matinella L, Simpson AJ, et al. (2000). Identification of planorbids from Venezuela by polymerase chain reaction amplification and restriction fragment length polymorphism of internal transcriber spacer of the RNA ribosomal gene. Mem. Inst. Oswaldo Cruz 95: 171-177.

Capron A (1993). La bilharziose: du papyrus à 1' ordinateur. Le généraliste 1411: 8-18.

Da Silva D, Spada RG, Sobral-Hamaguchi SS, Abdel-Hamid Z, et al. (2004). Biomphalaria tenagophila: genetic variability within intermediate snail hosts susceptible and resistant to Schistosoma mansoni infection. Parasite 11: 43-49.

Dias LCS, Glasser CM, Etzel A, Kawazoe U, et al. (1988). The epidemiology and control of Schistosomiasis mansoni where Biomphalaria tenagophila is a snail host. Rev. Saúde Pública 22: 462-463. 
Dice LR (1945). Measures of the amount of ecological association between species. Ecology 26: 297-302.

Ellsworth DL, Rittenhouse KD and Honeycutt RL (1993). Artifactual variation in randomly amplified polymorphic DNA banding patterns. Biotechniques 14: 214-217.

Hubendick B (1958). A possible method of schistosome-vector control by competition between resistant and susceptible strains. Bull. World Health Organ. 18: 1113-1116.

Jannotti-Passos LK and de Souza CP (2000). Susceptibility of Biomphalaria tenagophila and Biomphalaria straminea to Schistosoma mansoni infection detected by low stringency polymerase chain reaction. Rev. Inst. Med. Trop. São Paulo 42: 291-294.

Jurberg P, de Vasconcellos MC and Mendes NM (1989). Plants used as molluscicides: a critical view. Mem. Inst. Oswaldo Cruz 84 (Suppl 1): 76-83.

Knight M, Miller AN, Patterson CN, Rowe CG, et al. (1999). The identification of markers segregating with resistance to Schistosoma mansoni infection in the snail Biomphalaria glabrata. Proc. Natl. Acad. Sci. U. S. A. 96: 1510-1515.

Knight M, Ongele E and Lewis FA (2000). Molecular studies of Biomphalaria glabrata, an intermediate host of Schistosoma mansoni. Int. J. Parasitol. 30: 535-541.

Lardans V and Dissous C (1998). Snail control strategies for reduction of schistosomiasis transmission. Parasitol. Today 14: 413-417.

Larson SE, Anderson PL, Miller AN, Cousin CE, et al. (1996). Use of RAPD-PCR to differentiate genetically defined lines of an intermediate host of Schistosoma mansoni, Biomphalaria glabrata. J. Parasitol. 82: 237-244.

Mascara D, Kawano T, Magnanelli AC, Silva RP, et al. (1999). Schistosoma mansoni: continuous variation in susceptibility of the vector snail of schistosomiasis, Biomphalaria tenagophila I. Self-fertilization-lineage. Exp. Parasitol. 93: 133-141.

Matioli SR and de Brito RA (1995). Obtaining genetic markers by using double-stringency PCR with microsatellites and arbitrary primers. Biotechniques 19: 752-756, 758.

Matioli SR and Passos-Bueno MR (2001). Métodos Baseados em PCR para Análise de Polimorfismos de Ácidos Nucléicos. In: Biologia Molecular e Evolução (Matioli S, ed.). Holos, Ribeirão Preto, 156-157.

Miller AN, Ofori K, Lewis F and Knight M (1996). Schistosoma mansoni: use of a subtractive cloning strategy to search for RFLPs in parasite-resistant Biomphalaria glabrata. Exp. Parasitol. 84: 420-428.

Mott KE (1989). Contrasts in the control of schistosomiasis. Mem. Inst. Oswaldo Cruz 84 (Suppl 1): 3-19.

Mulvey M and Vrijenhoek RC (1982). Population structure in Biomphalaria glabrata: examination of an hypothesis for the patchy distribution of susceptibility to schistosomes. Am. J. Trop. Med. Hyg. 31: 1195-1200.

Mulvey M and Woodruff DS (1985). Genetics of Biomphalaria glabrata: linkage analysis of genes for pigmentation, enzymes, and resistance to Schistosoma mansoni. Biochem. Genet. 23: 877-889.

Newton WL (1955). The establishment of a strain of Australorbis glabratus which combines albinism and high susceptibility to infection with Schistosoma mansoni. J. Parasitol. 41: 526-528.

Oliveira AL, da Silva D, Zanotti-Magalhaes EM, Abdel-Hamid AZ, et al. (2008). Schistosome/mollusk: genetic compatibility. Genet. Mol. Res. 7: 518-526.

Paraense WL (1987). Control of Schistosomiasis mansoni: an outlook from current expectation. Mem. Inst. Oswaldo Cruz 82 (Suppl 4): 1-12.

Paraense WL and Correa LR (1978). Differential susceptibility of Biomphalaria tenagophila populations to infection with a strain of Schistosoma mansoni. J. Parasitol. 64: 822-826.

Paraense WL, de Alencar JT and Correa LR (1983). Planorbid distribution and the prevalence of schistosomiasis mansoni in the State of Espírito Santo. Mem. Inst. Oswaldo Cruz 78: 373-384.

Raghavan N, Miller AN, Gardner M, FitzGerald PC, et al. (2003). Comparative gene analysis of Biomphalaria glabrata hemocytes pre- and post-exposure to miracidia of Schistosoma mansoni. Mol. Biochem. Parasitol. 126: 181-191.

Richards CS and Merritt JW Jr (1972). Genetic factors in the susceptibility of juvenile Biomphalaria glabrata to Schistosoma mansoni infection. Am. J. Trop. Med. Hyg. 21: 425-434.

Richards CS, Knight M and Lewis FA (1992). Genetics of Biomphalaria glabrata and its effect on the outcome of Schistosoma mansoni infection. Parasitol. Today 8: 171-174.

Riedy MF, Hamilton WJ III and Aquadro CF (1992). Excess of non-parental bands in offspring from known primate pedigrees assayed using RAPD-PCR. Nucleic Acids Res. 20: 918.

Rollinson D, Stothard JR, Jones CS, Lockyer AE, et al. (1998). Molecular characterisation of intermediate snail hosts and the search for resistance genes. Mem. Inst. Oswaldo Cruz 93 (Suppl 1): 111-116.

Santos FR, Pena SD and Epplen JT (1993). Genetic and population study of a Y-linked tetranucleotide repeat DNA polymorphism with a simple non-isotopic technique. Hum. Genet. 90: 655-656.

Schall VT, de Vasconcellos MC, de Souza CP and Baptista DF (1998). The molluscicidal activity of Crown of Christ (Euphorbia splendens var. hislopii) latex on snails acting as intermediate hosts of Schistosoma mansoni and Schistosoma haematobium. Am. J. Trop. Med. Hyg. 58: 7-10. 
Spada RG, da Silva D, Abdel-Hamid AZ, Sobral-Hamaguchi SS, et al. (2002). Genetic markers between Biomphalaria glabrata snails susceptible and resistant to Schistosoma mansoni infection. Mem. Inst. Oswaldo Cruz 97 (Suppl 1): 53-58.

Spatz L, Vidigal THDA, Caldeira RL, Dias Neto E, et al. (1999). Study of Biomphalaria tenagophila tenagophila, B. $t$. guaibensis and $B$. occidentalis by polymerase chain reaction amplification and restriction enzyme digestion of the ribosomal RNA intergenic spacer regions. J. Moll. Stud. 65: 143-149.

Teles HMS and Vaz JF (1987). Distribuição de Biomphalaria glabrata (Say, 1818) (Pulmonata, Planorbidae) no Estado de São Paulo, Brasil. Rev. Saúde Pública 21: 508-512.

Vidigal THDA, Caldeira RL, Simpson AJG and Carvalho OS (2000). Further studies on the molecular systematics of Biomphalaria snails from Brazil. Mem. Inst. Oswaldo Cruz 95: 57-66.

Winnepenninckx B, Backeljau T and De Wachter R (1993). Extraction of high molecular weight DNA from molluscs. Trends Genet. 9: 407.

World Health Organization (1993). WHO Expert Committee on Control of Schistosomiasis. WHO Techn. Rep. Ser. 830, Geneva.

Zanotti-Magalhães EM, Magalhaes LA and de Carvalho JF (1991). Relationship between the pathogenicity of Schistosoma mansoni in mice and the susceptibility of the vector mollusc. I. Cercariae infectivity and worm burden. Rev. Saúde Pública 25: 359-366.

Zanotti-Magalhães EM, Magalhaes LA and de Carvalho JF (1993). Relationship between the pathogenicity of Schistosoma mansoni in mice and the susceptibility of the mollusk vector. II. Number of eggs in feces and number and size of granuloma in visceras. Rev. Saúde Pública 27: 412-420.

Zanotti-Magalhães EM, Magalhaes LA and de Carcalho JF (1997). Relationship between pathogenicity of Schistosoma mansoni in mice and the susceptibility of the vector mollusk. IV. Infectiousness of miracidia. Rev. Saúde Pública 31: 488-494. 